\title{
Michael Handelsman: estudioso, archivero y crítico de la prosa literaria escrita por mujeres en Ecuador
}

\author{
Michael Handelsman: Scholar, archivist and critic \\ of literary prose written by women in Ecuador
}

\section{Alicia Ortega Caicedo}

Universidad Andina Simón Bolívar, Sede Ecuador, Quito

DOI: https://doi.org/10.32719/13900102.2019.45.3

Fecha de recepción: 17 enero 2019

Fecha de aceptación: 9 abril 2019 
El lector atento ba de preguntar

cómo se mide la calidad, cuántas escritoras hacen falta

para que el Ecuador reconozca su presencia y qué constituye una expresión literaria aceptable y legitima

Michael Handelsman, Género, raza y nación

\section{RESUMEN}

Este trabajo tiene como propósito reconocer y destacar el notable aporte realizado por el crítico Michael Handelsman en el estudio de la narrativa (ensayística y de ficción) escrita por mujeres en Ecuador. Interesa resaltar los alcances de una labor empeñada en situar la escritura de mujeres en el terreno de la esfera cultural y política, de su impacto en la escena pública y social, en el horizonte de sus condiciones de posibilidad de producción, así como de circulación y recepción. Los escritos de Handelsman son atendidos (en los que estudia ensayos, novelas, cuentos y revistas escritas por mujeres ecuatorianas) con el propósito de observar sus estrategias de lectura que lo llevan a pensar la literatura como un escenario de lucha para las mujeres escritoras: espacio de autorepresentación, de resistencia y producción de conocimiento, en tensión con un sistema de valores de origen patriarcal. Sobre todo, este trabajo es un homenaje y tributo a la tarea que Michael Handelsman ha desempeñado de manera sostenida durante algunas décadas, con generosidad y lucidez en la búsqueda y construcción de su corpus objeto de estudio. Un corpus disperso en bibliotecas, archivos, revistas, antologías, que Handelsman ha sabido ubicar, atender, cuidar, sistematizar, periodizar, valorar, poner en debate, generar filiaciones e insistentemente señalar la existencia y alcances de esa valiosa, y a veces olvidada tradición narrativa producida en Ecuador por escritoras mujeres.

PaLABRAS CLAVE: Michael Handelsman, Ecuador, narrativa, escritoras, novelistas, cuentistas, ensayistas, revistas literarias feministas, escritura y género, literatura afroecuatoriana.

\section{ABSTRACT}

This paper intends to recognize and highlight the outstanding input made by critic Michael Handelsman in his study on narrative (both essayistic and fictional) written by women in Ecuador. It is important to highlight the scope of a work committed to place women's writing in the cultural and political sphere and show its impact on the public and social scene, in the horizon of its production, circulation and reception possibilities. Handelsman's writings (where he studies essays, novels, short stories and magazines written by Ecuadorian women) are approached with the purpose of observing his reading strategies, which lead him to conceive Literature as a struggle scenario for female writers: a space of self-representation, resistance and production of knowledge, in tension with a system of patriarchal values. Above all, this paper is a tribute to the task continually performed by Michael Handelsman for some decades, with generosity and lucidity, in the search and construction of the corpus that constitutes its object of study. It is a corpus scattered through libraries, archives, magazines, anthologies, which Handelsman has located, attended to, taken care of, systematized, periodized, valued, placed for debate, generated

\section{8 / KIPUS}


affiliations therewith, always insisting on the existence and scope of the valuable -and sometimes forgotten narrative tradition- produced in Ecuador by female writers.

KEYwORDS: Michael Handelsman, Ecuador, narrative, female writers, novelists, storytellers, essayists, feminist literary magazines, writing and gender, Afro-Ecuadorian Literature.

El aporte REALIZAdo por Michael Handelsman en el campo de los estudios literarios, acerca de la narrativa escrita por mujeres en Ecuador, es fundamental. Amazonas y artistas. Un estudio de la prosa de la mujer ecuatoriana, dos tomos, publicado por la Casa de la Cultura Ecuatoriana, Núcleo del Guayas, en 1978 (parte de la Colección Letras del Ecuador dirigida por Rafael Díaz Ycaza), ${ }^{1}$ es un esfuerzo logrado y pionero que busca demostrar la existencia de una significativa tradición narrativa en Ecuador producida por escritoras mujeres. Significativa, lo expresó Handelsman en varias ocasiones, no por razones numéricas sino por el impacto, presencia y resonancia de ese corpus en el campo cultural ecuatoriano. Vale reconocer de entrada el afán de Michael por polemizar con una canónica tradición crítica, empeñada en desconocer, minimizar o mitificar el aporte de muchas de las escritoras ecuatorianas.

Desde un inicio, el explícito interés de Michael fue llenar el vacío que advirtió en torno a investigaciones que apuntaran a destacar y estudiar el rol cumplido por la mujer ecuatoriana en el ámbito de la prosa literaria (ensayo y ficción). Pensar la escritura con marca de género, en diálogo con el rol social de las mujeres, implica un trabajo que sitúa la escritura en el terreno de la esfera cultural y política. Es sabido que históricamente, más aún en otros tiempos, las mujeres escribieron en condiciones muy diferentes a las de los hombres. De allí las luchas protagonizadas por ellas para lograr perseverancia y alcanzar reconocimiento. Virginia Woolf formuló su célebre reivindicación de una habitación propia para las escritoras, y en

1. Esta investigación corresponde, inicialmente escrita en inglés, a su tesis de doctorado de 1976 en la Universidad de Florida. Así rememora, casi cinco décadas después de su primer contacto con Ecuador: "Mi primer tema fue las escritoras ecuatorianas en prosa, que luego publicó la Casa de la Cultura. En los 70 había interés por las escritoras latinas, pero en Ecuador casi no se hablaba de eso, la gente decía: 'No, aquí no escriben prosa sino una poesía sentimentaloide que no sirve'... Pero yo seguía encontrando referencias de mujeres que estaban escribiendo desde finales del siglo XIX. Luego fue el proyecto del modernismo, la gente también me decía que llegó muy tarde, que solo había cinco poetas, los decapitados, pero yo encontraba lo contrario" (Handelsman en Murga 2018, $3)$. 
general para las mujeres intelectualmente activas, justamente en función de modificar sus condiciones de trabajo: "una mujer debe tener dinero y un cuarto propio para escribir ficción” (Woolf 2013, 20). En este horizonte de pensamiento, ha interesado a Handelsman reconocer la función pública de la escritura de mujeres, entender la prosa como un "foro" que posibilita la puesta en circulación y el debate en torno a las preocupaciones y problemas de mayor relieve que atañen a la vida de ellas. En suma, su tarea crítica no ha dejado de pensar la literatura como un espacio atravesado por una serie de condicionamientos sociales, culturales, políticos, históricos. Es decir, indagar respecto a las condiciones de posibilidad de una escritura de mujer, analizar el ambiente propicio para comenzar a escribir con constancia y conciencia de objetivos específicos, explorar la emergencia de una génesis literaria entre las ecuatorianas constituyen el escenario de su reflexión en la tarea que de manera sostenida ha ejercido nuestro ecuatorianista en su recorrido literario. Por ello, la mirada de Handelsman ha sabido atender la producción textual en consideración de su complejo circuito de producción, circulación y recepción/consumo, puesto que entiende la esfera literaria como un escenario de lucha para las mujeres: lucha por el poder representacional, espacio de autorrepresentación, resistencia y producción de conocimiento, en tensión, por lo general para el caso de escrituras de mujeres, con un sistema de valores de origen patriarcal.

En la perspectiva de trabajo arriba referida, Handelsman ha leído la prosa objeto de su estudio, por un lado, a la luz de lo que han dicho las mujeres sobre ellas mismas y teóricos que han puesto el acento en la articulación literatura y sociedad, así como también en relación a lo que han hecho las ecuatorianas en el campo de la realidad social en términos de resistencias y conquistas (representatividad ecuatoriana en congresos, delegaciones, comisiones internacionales de mujeres, Código de Trabajo, historia de la educación en el país), como desde el punto de vista de la teoría feminista. El trabajo de archivo realizado por Handelsman, en bibliotecas públicas y privadas, hemerotecas, instituciones varias y universidades, resulta clave al momento de brindarnos un valioso legado bibliográfico constituido por nombres de escritoras (algunas olvidadas, otras desconocidas), títulos de libros, artículos, periódicos, revistas, años de publicación, certámenes, perfiles y semblanzas, entrevistas, datos biográficos y articulaciones históricas; en suma, un acumulado de elementos que permite configurar eso que llamamos literatura al tiempo que problematiza lecturas 
cargadas de prejuicios socioculturales. Sabemos que la literatura no es algo dado, puesto que todo objeto de estudio resulta de una mirada valorativa que recorta y construye un corpus, pone en relación unos textos con otros, genera un diálogo entre ellos, reconoce genealogías y tradiciones, en función de poner los textos a discusión, devolverlos a la escena pública, restituirles su potencia interpeladora, dotarlos de presente y convertirlos así en objeto de reflexión y renovadas lecturas. Asumida así la tarea del investigador, la crítica tiene entonces una función creativa: "inventa una literatura (una perspectiva, un orden) a partir de las obras" (Paz 1971, 41). Como bien señala Handelsman en las palabras que cierran la "Introducción" de Amazonas y artistas: "el análisis y la bibliografía que ofrecemos son suficientemente detallados para dar a futuros investigadores una idea clara de las obras más importantes de prosa que fácilmente pueden ser localizadas. Además, con este trabajo esperamos que salgan a luz un nuevo interés en evaluar desde múltiples puntos de vista a las mujeres del Ecuador" (13). Así, en el libro mencionado, Handelsman parte por contrastar la imagen positiva de la figura histórica - "un estereotipo femenino idealizado"- con la imagen negativa de la mujer de letras (Handelsman 1978, 15-33.). ${ }^{2}$ Observa que históricamente las escritoras no se han realizado por completo, porque usualmente se les ha negado las oportunidades indispensables: prejuicios culturales, injusticias y contradicciones sociales, violencia institucionalizada y mecanismos de opresión, conflicto de intereses entre los roles de madre y escritora, marcos legales que no cuidan de la misma manera los derechos de todos los ciudadanos, a lo que se suma la consabida dificultad para publicar en nuestro medio, los pocos lectores y las limitaciones económicas que complican la dedicación a la escritura.

2. En "Heroínas históricas y escritoras de prosa...", observa Handelsman, por ejemplo, que las Amazonas, la princesa Pacha, las heroínas de la Independencia -Manuela Sáenz, la Marquesa de Solanda, Manuela Cañizares-, la santa Mariana de Jesús forman la esencia de la historia ecuatoriana: el núcleo, en palabras de Benjamín Carrión, de un "pueblo hijo de mujeres" (B. Carrión, El cuento de la patria. Breve historia del Ecuador, citado por M. Handelsman). Sin embargo, lo que pone en cuestión Handelsman es que a la mirada del crítico ecuatoriano se trata de un heroísmo que se define más por la pasión que por la acción. "Parece paradójico que la posición ocupe una posición ilustre en la historia y, a la vez, una posición tan ínfima en la literatura. Además, mientras que la supuesta participación dinámica de la mujer en la historia ecuatoriana podría dar la impresión que existe un ambiente propicio para el pleno desarrollo de la mujer, el vacío que se encuentra en la literatura, en cambio, tiende a negar en parte este concepto del 'pueblo hijo de mujer' " $(1978,21)$. 
Puesto que ha sido una recurrente preocupación de Handelsman pensar las resonancias sociales de una escritura de carácter público, ubica el crítico ecuatorinianista como inicial de una tradición a Dolores Veintimilla de Galindo y Marietta de Veintimilla, en la perspectiva de una reflexión que atiende los obstáculos que esas escritoras debieron soportar, los enfrentamientos que lideraron, las polémicas y controversias que desataron, precisamente porque sus publicaciones fueron reconocidas en la escena social como escrituras de mujer. No olvidemos que, en palabras de Marguerite Duras, "no se puede escribir sin la fuerza del cuerpo" (1994, 26). Handelsman se pregunta por los alcances de una escritura provocada por mujeres que asumen el desafío de ser "ciudadanas dinámicas, dispuestas a defender sus derechos e ideales humanos” (1978, 41). Qué ámbitos del mundo y de la vida tocan esas escrituras, qué ideas ponen en movimiento en la escena social, es lo que interesa al crítico examinar. Uno de sus empeños ha sido reconocer el aporte de escritoras que han trascendido como antecedentes y precursoras de una prosa que rompe con el horizonte de expectativas socialmente admitido para la escritura de mujeres.

Las revistas feministas que circularon durante las primeras décadas del siglo pasado constituyen un valioso archivo que Handelsman investiga, ordena y periodiza, con el ánimo de comprender el rol que cumplieron las mujeres bajo el impacto de las reformas liberales. Se trata de un período que fue propicio para que muchas mujeres decidieran escribir con el claro deseo de comunicarse con un público lector:

Las revistas feministas fueron esenciales en el progreso literario de las escritoras del Ecuador porque crearon un ambiente de solidaridad y unidad femeninas en el cual las autoras pudieron superar las dudas y los temores que anteriormente a muchas les había desalentado para publicar. Además, en cuanto al contenido, aparte de haber sido un testimonio de las mayores preocupaciones de las mujeres durante aproximadamente cuarenta años, las revistas también eran un documento de gran importancia respecto a la mujer y su propia interpretación de sí misma y de su rol en la sociedad" (Handelsman 1978, 51).

Vale relevar que Handelsman otorga a las revistas, periódicos y suplementos literarios un papel fundacional en el proceso de emergencia y consolidación de una tradición literaria entre las ecuatorianas - "fuente de desarrollo literario femenino" califica el crítico al papel que cumplieron 
las revistas en el período estudiado-, en el sentido de comprender que los artículos preparados para aparecer en medios de publicación periódica son, por su propia naturaleza genérica, textos de corta extensión, que no requieren un esfuerzo continuo de escritura, que suelen responder a una demanda de contemporaneidad, inmediatez y urgencia. Esta observación no es pequeña, puesto que constituye una línea importante de reflexión acerca de la escritura de mujeres: una que se produce de manera interrumpida y fragmentada, durante los cortos entretiempos que dejan los saltos y breves pausas entre una y otra actividad. El recorrido que organiza Handelsman a lo largo de casi cuatro décadas, pone de relieve los vínculos entre los propósitos oficiales de las revistas y sus complicidades con el pensamiento feminista, las redes de solidaridad entre las escritoras de diferentes procedencias geográficas a nivel continental, así como los espacios de aprendizaje y empoderamiento en la escritura no solamente con marca de género sino que se quiere portadora de una conciencia moderna. En el curso de esta suerte de mapeo, el crítico destaca títulos de publicaciones, nombres de las intelectuales que cumplieron un representativo rol como escritoras, portavoces, editoras, gestoras, promotoras y pensadoras de impacto político en la escena pública -Zoila Ugarte de Landívar, Rosa Borja de Icaza, Victoria Vásconez Cuvi, María Angélica Idrovo, Rosaura Emelia Galarza, entre otras-.

Cada uno de los seis capítulos que hacen parte de los dos tomos de Amazonas y artistas centra su atención en la producción textual alrededor de un género literario en concreto. Lo que resulta especialmente relevante de esta decisión para organizar el material del que dispone el crítico ha sido notar que el género elegido (en función de sus características formales) devino dispositivo de formación, en el curso del desarrollo literario de las escritoras. Comprendemos entonces que las revistas, en sus diferentes períodos, dieron el impulso inicial para que las mujeres reconocieran el medio desde donde podían escribir públicamente en un momento de aprendizajes, concientización y descubrimientos. El ensayo, en esta línea de ideas que nos propone Handelsman, aparece como un segundo momento en la creación de una escritura de carácter sostenido y no esporádico, que se abre a nuevos intereses (estéticos y artísticos) además de aquellos relativos a cuestiones sociopolíticas. En el lapso que antecede el fin de la Segunda Guerra Mundial, nuestro crítico destaca la ensayística de Hipatia Cárdenas, Victoria Vásconez Cuvi, Rosa Borja de Icaza y Zoila 
Rendón, ${ }^{3}$ como un acumulado bibliográfico que da cuenta de un amplio abanico de preocupaciones que activa y moviliza la escritura ensayística: feminismo y marianismo, derecho al sufragio, el tema de la igualdad ante la ley en los códigos ecuatorianos, política pacifista, entre otros. A partir de mediados del siglo XX hasta el presente de la escritura del libro que venimos comentando, Handelsman destaca el trabajo ensayístico de Piedad Larrea y Lupe Rumazo. Dos pensadoras que ensayan una reflexión de carácter metaliterario, que se pregunta por el estatuto de la literatura en la producción de una escritura que cruza la reflexión teórica, el juicio valorativo, el documento testimonial en relación al propio quehacer ensayístico. Ellas se reconocen lectoras que escriben y valoran desde una sensibilidad en consonancia con los debates más contemporáneos, claramente posicionadas a partir de un saber y un lugar de enunciación marcados por el horizonte hispanoamericano y una modernidad que se quiere de resonancia universal.

A propósito de la producción novelística, Handelsman advierte que, a diferencia del periodismo y el ensayo polémico, la novela cuenta con un número menor de escritoras. Son quince las novelas que focalizan la atención del capítulo, ${ }^{4}$ leídas como expresión de "literatura feminista"

3. En una nota a pie de página del capítulo dedicado al ensayo, Handelsman señala que en el mismo "solo analiza las obras escritas por Cárdenas, Vásconez, Borja y Rendón porque, a diferencia de otras escritoras de la misma época (i. e., María Luisa Calle, Zoila Ugarte de Landívar, Blanca Martínez de Tinajero, Delia Ibarra de Dueñas, María Piedad Castillo de Leví y numerosas mujeres más que prefirieron usar seudónimos), ellas publicaron colecciones enteras de sus artículos y ensayos, lo cual hace que su prosa sea más accesible. Debe notarse que existe una gran cantidad de prosa escrita por mujeres en los periódicos del Ecuador. Puesto que este material es similar a las obras de Cárdenas, Vásconez, Borja y Rendón (por lo menos en cuanto a los propósitos y los puntos de vista), estas cuatro mujeres pueden considerarse representativas de las escritoras activas durante los años 1922-1945" (Handelsman 1978, 120).

4. Las novelas estudiadas en el capítulo "La novela", tomo II de Amazonas y artistas, son: En la paz del campo (1940), Purificación (1942) y Luz en la noche de Blanca Martínez de Tinajero, La pena fuimos nosotras (1953) de Mireya de Bravomalo, Juventud inmolada (1954) de Bertha de Izurieta, Lo que deja la tarde (1955) de Matilde de Ortega, Sangre en las manos (1959) de Laura Pérez de Oleas Zambrano, Manuela Sáenz (1963) de Raquel Verdesoto de Romo Dávila, La profesora (1965) de Enriqueta Velasco, A noventa millas, solamente (1969) de Eugenia Viteri, Yoimar (1974) de Mireya Insua. Las novelas Hambre rubia (Nelly Espinoza de Orellana, 1959, ganó el primer premio del Certamen Literario Internacional del "Círculo de Escritores y Poetas Iberoamericanos", 1958, en Nueva York), La casa de tía Berta (Ana María Iza, 1974) y Verónica: historia de amor 
en el trabajo con la imagen de mujer que componen y las preocupaciones que las escritoras desarrollan. A pesar de los años transcurridos, en la perspectiva de periodización histórica y puesta en relación de unas obras con otras que desarrolla el crítico, las condiciones de producción de escritura parecen no haberse modificado de manera sustancial para las mujeres: tradicionales prejuicios sociales, falta de casas editoriales, insuficiente tiempo para la dedicación al trabajo literario. En la paz del campo (1940) de Blanca Martínez de Tinajero, Las penas fuimos nosotras (1953) de Mireya de Bravomalo, Lo que deja la tarde (1955) de Matilde de Ortega, Manuela Sáenz (1963) de Raquel Verdesoto de Romo Dávila, A noventa millas solamente (1969) de Eugenia Viteri, Bruna, Soroche y los tíos (1973) de Alicia Yánez Cossío, son los títulos que de manera más seductora concentran la lectura de Handelsman. Una lectura interesada en destacar el impacto social, la importancia histórico-social, la reacción pública de las novelas estudiadas, el pulso de una escritura que arriesga en la exploración de temáticas provocadoras y desafiantes (la explotación sexual de las mujeres, el aborto, los niños abandonados, el conflicto con las creencias sociales convencionales, el trabajo con arquetipos femeninos, la emergencia de nuevos comportamientos sexuales). Para el crítico, la novela (como en el caso de las otras escrituras estudiadas) asume el rol de foro en la defensa de intereses feministas, así como la puesta en consideración de nuevos patrones de comportamientos.

En el libro con el que continuamos nuestro diálogo, Handelsman propone al cuento como un género de más larga tradición, puesto que inicialmente se publicaron en revistas y periódicos. ${ }^{5}$ Nombres de autoras, títulos, inquietudes feministas y ámbitos temáticos, innovaciones técnicas,

(Zoila María Castro, 1975) son mencionadas pero no analizadas puesto que "no ofrecen material relacionado con el feminismo", interés que guía la lectura del crítico.

5. Señala Handelsman que fueron muchas las mujeres que publicaron cuentos, durante el siglo pasado, en revistas y diarios nacionales y del exterior (i. e., Mercedes González de Moscoso, María Natalia Vaca, Nela Martínez, Carmen Vela de Manzano, Inés Barrera, Carmen Acevedo Vega, Mireya Ramírez). No obstante, indica, ese material pasó inadvertido porque las publicaciones periódicas rara vez llegan a un público amplio de lectores. Destaca también el crítico el rol cumplido por la Casa de la Cultura Ecuatoriana en la publicación de cuentos escritos por mujeres, en formato de libro y colecciones, o en revistas como Letras del Ecuador (Quito) o Cuadernos del Guayas (Guayaquil). En palabras de Handelsman, se trata de textos olvidados en archivos y bibliotecas que poca o nula atención crítica han recibido (Handelsman, 1978). 
coyunturas históricas se despliegan prolijamente en un capítulo que encontrará una notable continuidad en Diez escritoras ecuatorianas y sus cuentos, ${ }^{6}$ de 1982, antología editada por la Casa de la Cultura Ecuatoriana, Núcleo del Guayas, también parte de la Colección Letras del Ecuador. Se trata, esta, de una antología imprescindible puesto que contiene una detallada ficha biobibliográfica que antecede al cuento seleccionado de cada una de las diez escritoras incluidas. Antes de avanzar en la lectura de otros títulos, vale destacar que Amazonas y artistas se cierra con una "Conclusión" que con fuerza sostiene la imperiosa necesidad de reevaluar el papel que las ecuatorianas han tenido en las letras nacionales, con el evidente propósito de reconocer los nombres de las escritoras que han aportado en la consolidación de una tradición narrativa en el país, que han elaborado desde el discurso en prosa imágenes de mujer en el proceso de autorrepresentación y aprendizajes de modelos literarios que vienen del pasado. Ese segundo tomo ofrece también en sus páginas finales una exhaustiva bibliografía de las obras de escritoras ecuatorianas y acerca de las mujeres ecuatorianas, así como un listado de títulos sobre la mujer y una actualizada, al momento de su publicación, teoría crítica feminista.

Incursiones en el mundo literario del Ecuador (de 1987, publicado por la Universidad de Guayaquil) es una recopilación de diez estudios sobre diversos aspectos de las letras ecuatorianas; textos que, en palabras del autor, "marcan mi itinerario profesional" (modernismo, revistas literarias, escritoras nacionales, años sesenta). ${ }^{7}$ De este conjunto de ensayos, me interesa destacar el dedicado a la novela de Alicia Yánez Cossío, Yo vendo unos ojos negros (1979), texto publicado originalmente en la Revista Iberoame-

6. Las cuentistas que reúnen esta antología son: Carmen Acevedo Vega, Zoila María Castro, Aída González Harvilan, Violeta Luna, Estela Parral de Terán, Mireya Ramírez, Lupe Rumazo, Fabiola Solís de King, Eugenia Viteri, Alicia Yánez Cossío.

7. Los artículos incluidos en el libro son: "Resonancia del 'boom': Ecuador y el parricidio cultural de los 60", "En pos de un concepto de cultura nacional: el caso del Ecuador y La Bufanda del Sol", "Fernando Tinajero y su teoría del desencanto", "En busca de una mujer nueva: rebelión y resistencia en Yo vendo unos ojos negros de Alicia Yánez Cossío", "Benjamín Carrión y su concepto de identidad nacional ante los peligros de la penetración cultural", "La misión cultural de un suplemento literario de Guayaquil: inventario y análisis del Meridiano cultural", "Algunas acotaciones sobre el neoindigenismo de Porqué se fueron las garzas", "El secuestro del general, El pueblo soy yo y la desmitificación del caudillo", "El modernismo en las revistas del Ecuador: 1895-1930. Ensayo preliminar", "Medardo Ángel Silva. Redescubriendo a un modernista ecuatoriano y paladín del arte nacional". 
ricana en 1988. Luego de recordar en las palabras introductorias que "las letras ecuatorianas están vivas, aunque a veces olvidadas" $(1987,64)$, señala que una de sus figuras más representativas es una mujer: Alicia Yánez Cossío. Tras una lectura de sus primeras obras, Handelsman articula a la novela el tema de protesta feminista en términos de rebelión y resistencia. La protagonista de la novela es leída por el crítico como "mujer-símbolo", en la perspectiva de imaginar la mujer del futuro a partir de una suma de introspecciones, concientización feminista y el examen de la sociedad en su tiempo. Este último punto es fundamental en la novela y en la lectura que de ella propone Handelsman: la protagonista es una mujer que en el proceso de alcanzar libertad e independencia, la búsqueda de trabajo pone en evidencia los mecanismos de explotación y opresión propios de un sistema socioeconómico de corte capitalista: “Al leer Yo vendo unos ojos negros, queda claro que la explotación y la opresión sufridas por la mujer son sintomáticas en un mundo capitalista cuyos modos de producción han creado un sistema socioeconómico que depende de dicha explotación y opresión" (72). Esta lectura que reconoce la fundamental importancia de la realidad socio-económica al momento de pensar las relaciones entre hombres y mujeres haya eco en las palabras de una pensadora contemporánea como Silvia Federici en su ya clásico Calibán y la bruja: "la construcción de un nuevo orden patriarcal, que hacía que las mujeres fueran sirvientas de la fuerza de trabajo masculina, fue de fundamental importancia para el desarrollo del capitalismo. Sobre esta base pudo imponerse una nueva división sexual del trabajo que diferenció no solo las tareas que las mujeres y los hombres debían realizar, sino sus experiencias, sus vidas, su relación con el capital y con otros sectores de la clase trabajadora" (Federici 2015, 206).

En 1999 Handelsman publica Lo afro y la plurinacionalidad: el caso ecuatoriana visto desde su literatura. De este libro quiero destacar el capítulo dedicado a Jonatás y Manuela (1994), novela de carácter histórico de Argentina Chiriboga. En el párrafo que prácticamente cierra las conclusiones de Amazonas y artistas, nuestro crítico afirmaba lo siguiente:

[...] debe recordarse que los comentarios que hemos incluido respecto a la mujer en el Ecuador solo reflejan el punto de vista de las intelectuales de clase media, las mismas que provienen de los sectores urbanos. O sea, hasta la fecha las escritoras ecuatorianas han ofrecido a los lectores una interpretación limitada de la situación global de la mujer en el Ecuador; las 
indias, las montuvias y las mujeres marginales de la ciudad básicamente están ausentes" (Handelsman 1978, 98).

No resulta difícil advertir en ese párrafo una idea matriz que se activa en publicaciones posteriores, en el contexto de los debates subalternos y decoloniales que Handelsman pone en diálogo con una larga tradición del pensamiento latinoamericano, empeñado en generar categorías de conocimiento -sincretismo, transculturación, heterogeneidad, plurinacionalidad, entre otras- necesarias para comprender el trazo de una fisonomía cultural hecha de elementos provenientes de disímiles matrices culturales, que conviven por fuerza de la historia en conflicto y desiguales condiciones de participación. Jonatás y Manuela, a los ojos de Handelsman, es una novela que testimonia un Ecuador pluricultural y tiene como punto de partida la conciencia de que nuestro país pertenece a la diáspora africana. Una conciencia que problematiza la vieja certeza de relacionar al país de manera casi exclusiva con lo andino y lo indígena. Importa relevar en el análisis de Handelsman la preocupación por articular las dimensiones de clase social, género sexual, raza/nación, geografía, con el propósito de relevar la presencia vital de lo afro en la composición nacional. Se trata de una lectura que explícitamente se propone repensar el tema de la identidad nacional a la luz de los debates más contemporáneos, y la medular cronología de luchas y levantamientos liderados por los pueblos históricamente dominados y subalternizados. "Proyecto literario afro-feminista" afirma Handelsman con respecto a Jonatás y Manuela: "El afrocentrismo, el feminismo y la democratización constituyen, entonces, los pilares sobre los cuales Chiriboga construye su visión de la nación" (Handelsman 1999, 146). ${ }^{8}$

En el 2011 publica Handelsman, con el sello editorial Guaraguao, Género, raza y nación en la literatura ecuatoriana: hacia una lectura decolonial. Aquí, me interesan dos momentos. Comencemos con la lectura que el autor propone acerca de dos imágenes de mujer construidas por dos emblemáticos escritores ecuatorianos: la novela Baldomera (1938) de Alfredo Pareja Diezcanseco, y el cuento "La doble y única mujer” de Pablo

8. El título de la novela alude explícitamente a sus dos protagonistas, Manuela Sáenz y su esclava Jonatás: "De hecho, según la interpretación afrocéntrica de Chiriboga, se entiende que es Jonatás quien prepara a Manuela para su futura participación en las guerras de Independencia, pero a partir de una previa lucha contra la esclavitud" (Handelsman, 147). 
Palacio. El crítico parte por señalar que Baldomera es uno de los personajes que más entusiasmo ha despertado entre los lectores de quien ha ganado una reputación como creador ejemplar de mujeres de ficción. Sin embargo, desarrolla Handelsman, toda la complejidad de ser mujer, trabajadora, mulata pobre, hombruna y mal hablada, se pierde ante una "moral patriarcal", que designa a la mujer el exclusivo rol de una maternidad mitificada en nombre de la abnegación, el sacrifico y el orden. Bajo esta luz, Baldomera es leída como una novela profundamente problemática y ambivalente, que denuncia y a la vez defiende un mismo sistema social opresivo y explotador: "Lo que intensifica la traición sumergida dentro de una tra(d) ición sexista es la reputación de Pareja Diezcanseco y sus compañeros de los años treinta como pensadores progresistas y abiertos al cambio social" (14). Provocadora es también la lectura que propone acerca de la narradora y protagonista del cuento palaciano, a propósito de quien Handelsman ensaya dos posibles líneas de sentido: la construcción de una metáfora de la lucha interior y la multiplicidad inherente a la mujer, sobre la base de un cuerpo humano aparentemente deformado, es una interpretación. La otra lectura sugiere que "la doble y única mujer" podría tratarse de un homosexual que acepta su sexualidad híbrida y ha asumido la persona de un ser femenino. En todo caso, sobresale siempre en los acercamientos de Handelsman a la literatura ecuatoriana su deseo de provocar y desarmar lecturas ya posicionadas, así como también su vocación de sugestivas relecturas en relación a escritores y obras tenidas por canónicas.

En un segundo momento, del apartado pertinente al tema "Género", Handelsman reconoce un "potencial subversivo" en Las alcobas negras (1984) de Eugenia Viteri y La casa del sano placer (1989) de Alicia Yánez Cossío, en tanto reconoce en ellas una radical problematización del sistema de valores y conceptos falocéntricos, a partir del trabajo con el motivo del burdel y la prostitución. Como hemos destacado en los trabajos anteriores, la estrategia de lectura que privilegia Handelsman atiende el contexto en el que se sitúa y produce el texto en cuestión, así como su horizonte de recepción y lectura. Es por ello que especial relevancia tiene la puesta en diálogo con otras publicaciones, contemporáneas a las dos novelas mencionadas, que estudian la sexualidad de las mujeres en el país, así como la formación en 1982 del primer sindicato de prostitutas en Ecuador, el impacto del denominado postboom latinoamericano de los años ochenta y la recepción de los estudios de género en esa década. Ha sido 
siempre para Handelsman un importante detonante de lectura reconocer en la ficción el trabajo con nuevos horizontes de expectativas, en la posibilidad de imaginar "nuevas alternativas de actuar y de vivir que puedan conducir a las mujeres dentro y fuera de la ficción a la plena realización personal y colectiva como seres humanos" $(2011,82)$.

Como resulta evidente, el acucioso y cuidado trabajo de Michael Handelsman en su perseverante pesquisa tras las huellas de las escritoras ecuatorianas a lo largo del tiempo es invaluable para quienes somos herederos de ese legado: se trata de un trabajo crítico que funda una literatura, atiende sus mediaciones y circuitos de difusión -un ejemplo de ello es su lectura de tres antologías dedicadas a narradoras ecuatorianas: Antología de narradoras ecuatorianas (1997) de Miguel Donoso Pareja, Narradoras ecuatorianas de hoy: una antología crítica (2000) de Adelaida López y Gloria Da Cunha-Giabbai y Cuentan las mujeres: antología de mujeres ecuatorianas (2001) de Cecilia Ansaldo-(Handelsman 2005), sitúa la escritura en el debate público así como en el horizonte de sus apropiaciones, disputas, aprendizajes, tradiciones, genealogías, resonancias políticas y capacidad de interpelación en el presente. Su labor crítica e investigativa no ha dejado de ofrecer al público lector, de manera persistente, lúcida, generosa, un rico material e inventario bibliográfico, lecturas actualizadas y relecturas provocativas con el manifiesto propósito de enfatizar la centralidad de la mujer en la literatura ecuatoriana. *

\section{Bibliografía}

Duras, Marguerite. 1994. Escribir. Barcelona: Tusquets.

Federici, Silvia. 2015. Calibán y la bruja. Mujeres, cuerpo y acumulación originaria. Buenos Aires: Tinta Limón.

Handelsman, Michael. 1978. "Introducción”. En Amazonas y artistas. Un estudio de la prosa de la mujer ecuatoriana. T. I, 7-14. Guayaquil: Casa de la Cultura Ecuatoriana, Núcleo del Guayas.

—. 1978. "Heroínas históricas y escritoras de prosa: un contraste de imágenes femeninas en el Ecuador". En Amazonas y artistas. Un estudio de la prosa de la mujer ecuatoriana. T. I, 15-33. Guayaquil: Casa de la Cultura Ecuatoriana, Núcleo del Guayas.

—. 1978. "Las primeras escritoras de prosa en las letras ecuatorianas". En Amazonas y artistas. Un estudio de la prosa de la mujer ecuatoriana. T. I, 34-47. Guayaquil: Casa de la Cultura Ecuatoriana, Núcleo del Guayas. 
—. 1978. "Las revistas feministas: una fuente en el desarrollo literario de la mujer ecuatoriana". En Amazonas y artistas. Un estudio de la prosa de la mujer ecuatoriana. T. I, 48-84. Guayaquil: Casa de la Cultura Ecuatoriana, Núcleo del Guayas.

- 1978. "El ensayo". En Amazonas y artistas. Un estudio de la prosa de la mujer ecuatoriana. T. I, 85-125. Guayaquil: Casa de la Cultura Ecuatoriana, Núcleo del Guayas.

- 1978. "La novela", en Amazonas y artistas. Un estudio de la prosa de la mujer ecuatoriana. T. II, 5-52. Guayaquil: Casa de la Cultura Ecuatoriana, Núcleo del Guayas.

- 1978. "El cuento". En Amazonas y artistas. Un estudio de la prosa de la mujer ecuatoriana. T. II, 53-95. Guayaquil: Casa de la Cultura Ecuatoriana, Núcleo del Guayas.

- 1978. "Conclusión". En Amazonas y artistas. Un estudio de la prosa de la mujer ecuatoriana. T. II, 96-9. Guayaquil: Casa de la Cultura Ecuatoriana, Núcleo del Guayas.

—. 1982. Diez escritoras ecuatorianas y sus cuentos. Guayaquil: Casa de la Cultura Ecuatoriana, Núcleo del Guayas.

—. 1987. "En busca de una mujer nueva: rebelión y resistencia en Yo vendo unos ojos negros de Alicia Yánez Cossío”. En Incursiones en el mundo literario del Ecuador, 63-78. Guayaquil: Universidad de Guayaquil.

—. 1999. "Jonatás y Manuela: lo afroecuatoriano como discurso alternativo de lo nacional y lo andino". En Lo afro y la plurinacionalidad: el caso ecuatoriano visto desde su literatura, 113-53. Mississippi: University of Mississippi Press.

-.2005. "Las mujeres también cuentan en el Ecuador: reflexiones sobre tres antologías recientes de narradoras ecuatorianas y el lugar que estas ocupan en el imaginario nacional”. Revista Iberoamericana (Pittsburgh), n. ${ }^{\circ} 210$ (enero-marzo): 165-74.

—. 2011. "Baldomera y la tra(d)ición del orden patriarcal”. En Género, raza y nación en la literatura ecuatoriana: hacia una lectura decolonial, 13-26. Barcelona: Guaraguao.

—. 2011. "Una doble y única lectura de 'Una doble y única mujer' de Pablo Palacio”. En Género, raza y nación en la literatura ecuatoriana: hacia una lectura decolonial, 27-58. Barcelona: Guaraguao.

—. 2011. "Mujeres del Ecuador dentro y fuera del burdel: dos novelas y sus contextos de lucha y reivindicación". En Género, raza y nación en la literatura ecuatoriana: hacia una lectura decolonial, 59-86. Barcelona: Guaraguao.

Murga, Martha. 18 de julio de 2018. Entrevista a Michael Handelsman, "Handelsman tiene casi 50 años como ecuatorianista". Diario El Universo, sección Intercultural, 3 .

Paz, Octavio. 1971. Corriente alterna. México: Siglo XXI.

Woolf, Virginia. 2013. Un cuarto propio. Buenos Aires: Losada. 